\title{
The Effectiveness of Emotion Regulatory Training on Test Anxiety and Processing Efficiency of High School Girl Students
}

\author{
Amin Taghipour ${ }^{1}$, Shiva Razi ${ }^{2}$ \\ ${ }^{1}$ Faculty of Educational Sciences and Psychology, Mohaghegh Ardabili University, Ardabil, Iran \\ ${ }^{2}$ Faculty of Humanity Sciences, Boukan Azad University, Boukan, Iran
}

Email address:

amintaghipur@gmail.com (A. Taghipour),s.razi1967@gmail.com (S. Razi)

${ }^{*}$ Corresponding author

To cite this article:

Amin Taghipour, Shiva Razi. The Effectiveness of Emotion Regulatory Training on Test Anxiety and Processing Efficiency of High School Girl Students. International Journal of Neurologic Physical Therapy. Vol. 6, No. 2, 2020, pp. 17-22. doi: 10.11648/j.ijnpt.20200602.11

Received: March 7, 2020; Accepted: April 7, 2020; Published: September 3, 2020

\begin{abstract}
Emotional order, expresses the psychological and behavioral processes in which individuals affect their feelings and others. The Purpose of this study is determining effect of emotion regulation training on the test anxiety and processing efficiency among high school girls' students. a quasi-experimental design was selected to run this study and anxiety questionnaire developed by spilberger was used to collect data. The population of this study was the whole girls' students of Bonab's high schools. 44 samples were selected through multiple stage cluster sampling and assigned to two groups of experimental and control group. After the pretest, the participants in experimental group were given emotion regulation training based on gross model for one hour in 8 sessions. The control group did not receive any training in all these session. And there was no intervention. After the sessions, these groups were evaluated once again. Manova was used to analyze the data. Furthermore meaningful level is considered in all of the analyze $(p<0 / 05)$ for this research. Data analyzes showed that emotion regulation was effective for test anxiety and processing efficiency. Emotion regulation skills can be offered to students for enabling them to manage their anxiety at school.
\end{abstract}

Keywords: Emotion Regulation, Test Anxiety, Processing Efficiency

\section{Introduction}

Over the last decades, more emphasis is placed on the role of emotional regulation in Psychopathology [1]. Excitement is an internal data that affects our thoughts and behavior. Excitement is universal and appearing in one form throughout the people over the world. The faces of people in different cultures are similar in sadness, happiness, hatred and wonder. We may not understand each other's language, but we understand the excitement of each other from the forms of the face. This point reflects the importance of excitement in our daily life. Emotions play a vital role because they keep us alive. Positive excitements like joy, increase energy levels, increase self-esteem, power of decision-making, creativity, optimism and hope, endeavor and perseverance, resilience and tolerance to disadvantages and hardships and hard work. And then the physical and psychological health of the person becomes guaranteed. Instead, negative excitements such as sadness have the negative result, and reduce energy and confidence, the power of thought and decision, stagnation and frustration, disappointment and impatience, which increases physical and mental problems.

It should be noted that the experience of both positive and negative modes of excitement is an inseparable part of human life and it is necessary. But the dominant and persistent experience of negative emotions leads to mental disorders, such as depression and anxiety. One of the basic problems is that many people cannot control their excitement effectively. Psychological pathologists believe that failure in applying and refining emotional regulation skills predicts future mental health problems and can predispose children and adolescents to subsequent mental disorders; In addition, it is an important factor in the appearance of depression and anxiety [2]. 
Excitements are functional and adaptive phenomena that help the organism and apply behavior to the goals of the organism. And can disrupt cognitive and behavioral processes and direct attention to stimuli [3]. Evidence suggests that humans are born with a series of early emotional reactions, and although these emotional responses are similar in all cultures and communities and occur in response to internal and external stimuli, but people learn different strategies in response to stimuli. Therefore, two individuals do not show the same emotional responses to one stimulus [4].

Emotional responses provide important information about person's experience with others, with this information; humans learn to behave in the face of excitement, how to express emotional experiences verbally, and what strategies to respond to emotions and how to deal with others in the context of specific excitements. The study of literature and psychological studies shows that emotional regulation is an important factor in determining health and having successful performance in social interactions [4].

The emotional regulation includes all conscious and unconscious strategies that are used to increase, maintain, and reduce the emotional, behavioral and cognitive components of an emotional response, and refers to the ability to understand emotions, modify experience, and express emotions [5]. Since emotional regulation is an important part of every person's life, ability to control excitement is one of the most important capacities must to be learn [6]. Because any forms of deficiencies in the regulation of emotions can make a person vulnerable to mental disorders such as anxiety and depression [7].

The setting of excitement is a meta-diagnostic and metatheory process which affects a wide range of psychological problems from a variety of theoretical approaches. And refers to activities that allow individuals to monitor, evaluate, and modify the nature and duration of emotional responses [8].

According to Kappa [9], emotional regulation strategies significantly predicted the test anxiety, as a result of which his findings indicated that emotional regulation had a significant positive relationship with the test anxiety. Also, Sarason [10] showed that students' test anxiety was due to the lack of coping skills with excitement. But despite a large volume of research texts in the test anxiety, a few of research has focused on emotional adjustment strategies during the exam.

Carthage, Hearst, Apter and Grass [11], believe that anxiety disorders are a combination of real and perceived defects in the ability to adjust excitement. Exam anxiety occurs in abnormal cognitive conditions (such as disturbing perceptions and unrelated thoughts about examinations) nearby stressor education. These abnormal responses lead to extremely stressful situations, reduce performance, and reduce active memory [12]. According to researchers, how to evaluate an individual's cognitive system when dealing with a negative event is very important [13], Because knowing how cognitive experiences may vary for anxious people and how they relates to their performance can make the practitioners awareness of how these people can achieve their proper and expected level of performance. In order to better understand the relationship between anxiety and cognitive function of individuals [14], have proposed a theoretical model called the process efficiency theory. On this basis, processing efficiency is high, when a person can achieve the best performance by using few resources. Since anxious people spend more mental resources, their processing efficiency will be reduced further. Findings show that when an individual experiences anxiety, he may be able to maintain the effectiveness of the function, but this achievement is achieved nearby the expense of reducing the processing efficiency means consuming more processing resources; In other words, the processing efficiency refers to the amount of effort or used resources by person for performs the task and usually evaluated through the amount of mental effort or time spent [15].

Processing is a cognitive element, and the findings indicate that the processing efficiency is affected by the test anxiety. Anxiety is also an emotional problem. And the relationship between excitement and cognition has been the topic of interest from psychologists and researchers And attention to the discussion of emotion and recognition, and considering that the classroom is the place of multiple emotional experiences involves the excitement of success and failure of education, the acceptance or non-acceptance by friends and so on, caused the special attention of educators. Therefore, due to the lack of research in the study of emotion training based Grass's modeling, the test anxiety and the lack of emphasis on the role of emotional regulation training on the processing efficiency of performing this research seems necessary. In line with these studies and their results, the present study intends to answer this question that does train the excitement regulation affect on the test anxiety and girls' processing efficiency.

\section{Research Method}

The present research is a quasi-experimental type of causal research. Type of project in this research, is pre-test post-test design with control group, and the statistical population of this study included all 5893 female high school students in the city of Bonab in the academic year 2018/09/23 to 2019/09/22. From the mentioned population and according to the purpose of present study, samples of 44 people (22 controls and 22 experimental groups) were selected; the size of this sample follows this conditions: (1) significance level ( $\alpha=0.05)$, (2) community variance, (3) test power (0.92), and (4) effect volume $(0.50)$. The participants of this study were selected through multi-stage cluster sampling. First, Bonab city was divided geographically into four regions: north, south, east and west. And a girls' high school was randomly selected from northern region. From this high school, two classes were randomly selected and their students were assigned to both experimental and control groups. Research tools include:

1. Spielberger Exercise Anxiety Inventory: Anxiety Questionnaire was created by Spielberger (1980). This questionnaire has 20 items that describe the reaction before, during and after the examinations. The test anxiety questionnaire consists of two "worry" and "excitement" subtests that measure individual 
differences in test anxiety. Some of the items in this questionnaire are from the test anxiety scale, and others are provided by the inventors. Test anxiety questionnaire is a report and each person answers each material based on a four-dimensional scale ("almost never", "sometimes," "often," and "almost always"). This questionnaire has been translated and verified by Abolqasemi, Beigi and Narimani [7]; they obtained the coefficients of internal consistency, double-test, and test-retest (after four weeks) respectively $0.92,0.92$ and 0.90. Abolghasemi et al. [7] used anxiety test and definition of the test anxiety construct to validate this questionnaire. The correlation coefficient of the test anxiety inventory with the dissuasive and anxiety facilitator subtest in anxiety test, progression and structural definition respectively were $0.70,-0.46$ and 0.47, $(\mathrm{P}=0.01)$. In the present study, the Cronbach Alpha obtained at the pre-test and post-test stage was respectively 0.83 and 0.85 .

2. Information processing index test: This assignment is computerized in which trains with different colored wagons enter the station from the left, So that it is not visible for the moment and then from the right exits while the color of some of the wagons is changed. In other words, the color of some wagons changes in comparison with the moment of entry. Seven colors are used in these wagons. The purpose of the task, which is performed by pressing one or two keys, is whether the color of each wagon has been changed or not? During the train enters the station and disappears, the subject must remember the color of the wagons in order. Both data acquisition and processing are required in these tasks. The amount of processing and the amount of information needed to memorize increases according to the length of the train. The length of each train increases to six wagons. So there are 84 wagons for measurement. In this study, the number of correct responses is equal to the number of wagons that are correctly answered. The person's score is equal to the percentage of his correct judgments, for each correct wagon to be answered; 19.1 points are recorded for the subject. The scores and response time of each subject are recorded by the software and will be announced at the end. For obtain the each person's processing efficiency score of this test, the score of the correct answers is divided into spent time. For study the reliability, the test-retest method was used. Using this method, between the first performance and the second, 3 months interval was considered. The correlation coefficient obtained from the first and second performance was 0.86 [14]. In the present study, the correlation coefficient obtained from the first and second performance was 0.79 .

How to intervene and conduct research

In this research, after the sampling, the process was mentioned; both groups were evaluated by pretest. By this way, the members of the two groups completed the Spielberger Test Anxiety Inventory. After completing the test anxiety questionnaire, the subjects performed a one-to-one test of the information processing index (for evaluate the efficiency of their processing). After the pre-test completion, the intervention started. During the 8 sessions, the experimental group received two sessions per week and each session received 1 hour of thriller training, from early November to late December 2018, they received. During this period, the control group did not receive any training. The training was that each meeting was held with one goal and each session, while reviewing homework sessions, asked the subjects to complete assignments in the session itself. End of the sessions were with feedback from the same session. The training schedule is as follows:

Table 1. Objectives of the meetings.

\begin{tabular}{|c|c|c|}
\hline Session number & Title & The purpose of the meeting \\
\hline Session 1 & $\begin{array}{l}\text { Understand the primary } \\
\text { and secondary goals }\end{array}$ & $\begin{array}{l}1 \text { Familiarity of the members of the group with each other and the initiation of the relationship between the } \\
\text { leader of the group (advisor) and the members } 2 \text { - The statement of the main and secondary goals of the } \\
\text { group and the dialogue of the parties about personal and collective goals } 3 \text { - The expression of logic and } \\
\text { intervention stages } 4 \text { - The expression of the framework and rules of participation in the group, }\end{array}$ \\
\hline Session 2 & $\begin{array}{l}\text { A general } \\
\text { understanding of } \\
\text { excitement }\end{array}$ & $\begin{array}{l}\text { Recognition of emotion and motivational status through training of differences in the types of emotions, } \\
\text { information about different dimensions of excitement and short-term and long-term effects of excitement }\end{array}$ \\
\hline Session4 & Skills training & $\begin{array}{l}\text { A) preventing social isolation and avoiding b) teaching problem solving strategies; c) training interpersonal } \\
\text { skills (dialogue, self-expression, and conflict resolution), }\end{array}$ \\
\hline Session5 & Stop thinking & 1) Stop rumination and worry 2) Attention training, \\
\hline Session6 & $\begin{array}{l}\text { Identify incorrect self- } \\
\text { assessments }\end{array}$ & A) Identification of miscalculations and their effects on emotional states; b) Re-evaluation strategy training; \\
\hline Session8 & Assessment & $\begin{array}{l}\text { 1- Assessing the achievement of individual and group goals. 2- Applying skills learned in natural } \\
\text { environments outside the session. 3- Examining and removing barriers to doing tasks. }\end{array}$ \\
\hline
\end{tabular}

After the end of the 8th session of intervention, the members of the experimental group and the control group were evaluated in the same manner as the pre-test, with a post-test. And again completed the Spielberger test anxiety 
questionnaire and conducted the test of the information processing index. In order to investigate the results of the hypotheses, multivariate analysis of variance (MANOVA) was used for statistical analysis and data normalization was used by $M$ box tests and Levine test. In addition, in all analyzes, the significance level was considered to be $\mathrm{P}<0.05$.

\section{Findings}

In table 2, descriptive information (mean and standard deviation) related to the variables test anxiety and processing efficiency in the pretest and post-test phases are shown in the two groups.

Table 2. Descriptive statistics of pre-test and post-test anxiety tests and processing efficiency.

\begin{tabular}{llllll}
\hline Variable index & group & the level & mean & Standard deviation & Number \\
\hline \multirow{4}{*}{ Test Anxiety } & experimentation & Pre-test & $49 / 63$ & $10 / 40$ & 22 \\
& group & Post-test & $39 / 5$ & $7 / 67$ & 22 \\
& & Pre-test & $51 / 63$ & $10 / 93$ & 22 \\
& Control group & Post-test & 49 & $10 / 69$ & 22 \\
Process Efficiency & experimentation & Pre-test & $0 / 22$ & $0 / 076$ & 22 \\
& group & Post-test & $0 / 27$ & $0 / 063$ & 22 \\
& Control group & Pre-test & $0 / 19$ & $0 / 048$ & 22 \\
\hline
\end{tabular}

To test the hypothesis that emotional regulation training affects test anxiety and processing efficiency, MANOVA analysis was used. The results of the main hypothesis review are shown in Table 3.

Table 3. The results of (MANOVA) on the mean of test anxiety and processing efficiency.

\begin{tabular}{|c|c|c|c|c|c|c|}
\hline index & Amount & F ratio & freedom Degree of hypotheses & Level P & Effect size & Test power \\
\hline Pillai\& Trace & $0 / 321$ & $4 / 607$ & 4 & $\mathrm{p}<0 / 001$ & $0 / 321$ & $0 / 91$ \\
\hline Wilks Lambda & $0 / 679$ & $4 / 607$ & 4 & $\mathrm{p}<0 / 001$ & $0 / 321$ & $0 / 91$ \\
\hline Hotelling\& Trace & $0 / 473$ & $4 / 607$ & 4 & $\mathrm{p}<0 / 001$ & $0 / 321$ & $0 / 91$ \\
\hline Roy \& Largest Root & $0 / 473$ & $4 / 607$ & 4 & $\mathrm{p}<0 / 001$ & $0 / 321$ & $0 / 91$ \\
\hline
\end{tabular}

Table 3 shows that there is a significant difference between test and control groups in terms or post-test of dependent variables at the level of $p<0 / 001$. Accordingly, it can be stated that at least one of the dependent variables (test anxiety and processing efficiency) is significant difference in the post-test between the two groups. To find out this difference, two variance analysis with one variables were performed by MANOVA, which the results of are listed in the table below. The effect size coefficient shows that $32 \%$ of the difference between the two groups is related to the experimental intervention. To test the hypothesis that the training of emotional regulation affects exam anxiety ANOVAs' analysis was used in the MANOVA text; the results are given in Table 4.

Table 4. Results of ANOVA analysis in MANOVA text on the mean scores of pretest and post test anxiety tests.

\begin{tabular}{lllllllll}
\hline $\begin{array}{l}\text { Source of } \\
\text { change }\end{array}$ & level & $\begin{array}{l}\text { Sum of } \\
\text { squares }\end{array}$ & $\begin{array}{l}\text { Freedom } \\
\text { degree }\end{array}$ & $\begin{array}{l}\text { Average } \\
\text { squares }\end{array}$ & F & $\begin{array}{l}\text { The significance } \\
\text { level }\end{array}$ & Effect size & $\begin{array}{l}\text { Test } \\
\text { power }\end{array}$ \\
\hline \multirow{2}{*}{ group } & Pre-test & 44 & 1 & 44 & $0 / 386$ & $0 / 538$ & $0 / 386$ \\
& Post-test & $992 / 75$ & 1 & $992 / 75$ & $11 / 46$ & $0 / 002$ & $0 / 09$ \\
\hline
\end{tabular}

The contents of Table 4 show that there is no significant difference in test anxiety in the test group at the level of $p$ $<0.05$. But in the post-test, there is a difference between the obtained significant levels (0.002). The coefficient of effect size indicates that $21 \%$ difference is related to experimental intervention. Also, the statistical test power in this study is 0.91. Also, to examine the hypothesis that the training of emotional regulation affects the processing efficiency; ANOVAs' analysis has been used in the MANOVA text. The results are presented in Table 5.

Table 5. Results of ANOVA analysis in MANOVA text on the scores mean of pre-test post-test processing efficiency.

\begin{tabular}{lllllllll}
\hline $\begin{array}{l}\text { Source of } \\
\text { change }\end{array}$ & level & $\begin{array}{l}\text { Sum of } \\
\text { squares }\end{array}$ & $\begin{array}{l}\text { Freedom } \\
\text { degree }\end{array}$ & $\begin{array}{l}\text { Average } \\
\text { squares }\end{array}$ & F & \multicolumn{2}{l}{$\begin{array}{l}\text { The significance } \\
\text { level }\end{array}$} & Effect size \\
\hline \multirow{2}{*}{ group } & Pre-test & $0 / 006$ & 1 & $0 / 006$ & $1 / 494$ & $0 / 22$ & $\begin{array}{l}\text { Test } \\
\text { power }\end{array}$ & $0 / 034$ \\
& Post-test & $0 / 022$ & 1 & $0 / 022$ & $6 / 185$ & $0 / 017$ & $0 / 22$ & $0 / 12$ \\
\hline
\end{tabular}

Table 5 shows that there is no significant difference in the pre-test variable of processing efficiency at the level $\mathrm{p}<0.05$. But in the post-test, there is significant difference (0.017). The effect factor coefficient shows that the 12 percent difference is related to the experimental intervention. Also, the statistical test power in this research is $0 / 68$.

\section{Discussion}

The aim of this study was to investigate the effect of emotional regulation training on test anxiety and processing efficiency among female high school students. The results of the research showed that excitement regulation training based 
on the Grass model, in reducing the test anxiety and increasing the efficiency of processing, it has been effective in students. These findings suggest that emotional regulation training is an effective strategy to reduce the test anxiety and thereby increase the processing efficiency.

The results of this study were compared with the findings of various studies such as Cartia [11], Abolqasemi [7] and Parksetal [12], it is same. In explaining these findings, we can say Given that anxiety disorders are a combination of real and perceived defects in the ability to regulate excitement [11], This result may have been due to the application of mind- awareness exercises and their particular impact on anxiety of individuals. It can be said that some of the people can exacerbate this feature due to the attention and focus on their minds and their thoughts, and in fact selfawareness. People can adjust and manage their excitement, and start the positive excitement and facilitators and they will control effective social communication strategies and will be flexibility inattention and decision making under stressful conditions, undesirable manner.

The test anxiety has two important components of concern and excitement [15]. On the other part of the training Grass's model based excitement to regulate the excitement, presented relaxation strategies and extend attention. And the effectiveness of this model can be attributed to these skills.

Also, based on the findings of this study, it became clear that emotional training also had an impact on the processing efficiency of students. In explaining this result we can say that the effectiveness of training emotional regulation on processing efficiency can be due to trying to cognitive change (changing person's thoughts about a position to change emotions), and skills to stop rumination and educate open assessment strategies. It is possible to attribute the cause of emotional disturbances to defects in cognitive controls, possibly, the inability to control negative excitement results from the existence of negative thoughts and beliefs about worries and the use of ineffective coping practices.

When a person faces an emotional situation, feeling good and optimistic is not enough to control the excitement the person also needs to have the best cognitive function in these situations. In principle, in adjusting the excitement, an optimal interaction of cognition and excitement is needed to deal with negative conditions [2]. Overall, given the cognition of the processing efficiency variable, the training of emotional regulation can be effective in this regard. Because human beings interpret it as they see it and cognitive interpretations determine the reactions of individuals.

\section{Conclusion}

Emotional anxiety and excitement are among the factors that greatly affect the performance of individuals in situations such as the position of the exam. These influences can be explored in two aspects: First, emotional changes create mental disorders that affect mental performance. This can lead to lack of concentration and attention, forgetfulness of learned content or interference with one another, this process will increase student anxiety. Second, the interpretation that these individuals have of emotional excitement affects on performance and their other excitements. If students have a high negative rating about excitement and they consider it as deterrent and destructive they will experience more anxiety. If individuals can control their excitement and evaluate them more positively, they will have less anxiety.

Among the limitations of this research, one can point out the limited sample to female students, the small size of the sample, the lack of a follow-up period, and the low power of generalization of quasi-experimental designs. If these limitations are removed, further results can be obtained in future research more accuracy. Also, given that the emotional debate and emotional regulation is an important issue, it is desirable that education and higher education officials pay close attention to the content of the curriculum in this field.

\section{References}

[1] Seligowski, Antonia V., et al. "Emotion regulation and posttraumatic stress symptoms: A meta-analysis." Cognitive behaviour therapy 44.2 (2015): 87-102.

[2] Gross, J. J. (2013). Emotion regulation: Taking stock and moving forward. American psychological association. 10 (3) $10-37$.

[3] Amiri, Isazdegan. "Modeling the structure of relationships between difficulty in regulating excitement, positive and negative emotions, and quality of sleep." Armaghane Danesh 22.2 (2017): 242-254.

[4] Esmaili, Leila, Aghaei, Asghar, Abedi, Mohammad Reza, Esmaili, Maryam (2011). The Effectiveness of Setting Excitement Training on the Mental Health of Epilepsy Girls. Thought and Behavior, Volume 5, No. 20. 42-31.

[5] Gross, J. J. (2007). Handbook of emotion regulation. New York, NY: Guilford Press.

[6] Amstadter، A. (2008) Emotion regulation and anxiety disorders، PsychopatholBehav Assess, 22 ، 211-221.

[7] Abolqasemi, Abbas; Beigi, Parvin; Narimani, Mohammad (2011). The Effectiveness of Two Cognitive Behavioral Educational Techniques and Exercise Adjustment Skills on Self-efficacy and Academic Adaptability of Students with Test Anxiety. Quarterly Journal of Educational Psychology, No. 90, pp. 42-21.

[8] Johnson, Sheri L., Charles S. Carver, and Daniel Fulford. "Goal dysregulation in the affective disorders." Emotion regulation and psychopathology: A transdiagnostic approach to etiology and treatment (2010): 204-228.

[9] Heidari, Alireza; Ehteshamzadeh, Parvin; Halajani, Fatemeh (2010). Relationship between emotional regulation, metacognition and optimism with students' test anxiety. New discoveries in psychology. No. 4, p. 19-7.

[10] Vimz، B. \&Pina، W. (2010) the assessment of emotion regulation: Improving construct. validily in research on psychopathology in yoth. Journal of psycholosicalbihaviour assessment, 10 (1): 169-178. 
[11] Carthy, T., Horesh, N., Apter, A., Gross, J. J. (2010). Patterns of Emotional Reactivity and Regulation in Children with Anxiety Disorders. PsychopatholBehav Assess, 32: 23-36.

[12] Parks - Stamm، E. Gollwitzer، P. M، \& Oettingen، G. (2010) Implemention intentions and test anxiety. Shielding academic performance from distraction. Journal of learning and individual differences ، 20: 30-33.

[13] Abolqasemi, Abbas; Golpour; Reza; Narimani; Mohammad; Ghamari; Hossein (2009). Study of impaired metacognitive beliefs with academic success of students with anxiety tests. Educational Studies of Ferdowsi University of Mashhad, Volume 10, Number 3, pp. 20-5.
[14] Moradi, Alireza; Cheraghi, Fereshteh; Farahani, Mohammad Naghi (2008). The effect of anxiety and how homework is presented on the efficiency of the processing and operation of active memory elements. Journal of Psychology, Tabriz University, Third Year, No. 11, pp. 33-20.

[15] Cheraghi, Fereshteh; Moradi, Alireza; Farahani, Mohammad Naghi (2008). Study of the effect of trait anxiety and high pressure position on processing efficiency and active memory performance. Journal of Behavioral Sciences, Volume 2, Issue 1, pp. 32-25. 